\title{
Self-Insurance and the Risk-Sharing Role of Money
}

Tsz-Nga Wong

"The inherent vice of capitalism is the unequal sharing of blessings."

-Winston Churchill address to the House of Commons, 1945

oney is well-acknowledged as a social construct to overcome the lack of coincidence of wants in a society. On top of its transactional role, the literature of monetary theory has also pointed out the role of self-insurance following the fact that money can be a vehicle for precautionary saving. ${ }^{1}$ Less is mentioned about money as a social construct to promote risk sharing among individuals. In this review, I will provide a simple mathematical model to illustrate this new insight. The model can be solved in closed form with paper and pencil. The material here is borrowed from some recent studies. ${ }^{2}$

In my "toy model" there are a lot of agents; each receives a constant flow of endowment but also faces uncertainty about the timing and the number of "liquidity shocks": when the shock hits, the agent needs to spend a big chunk of endowment. In real life, the liquidity shock

I have benefited from the comments of John Weinberg, Felix Ackon, Felipe Schwartzman, and Nicholas Trachter. The views expressed in this article are those of the author and do not necessarily represent the views of the Federal Reserve Bank of Richmond or the Federal Reserve System.

\footnotetext{
${ }^{1}$ See the seminal paper of Bewley (1980) and its corrigendum Bewley (1983) for the error in the existence proof pointed out by Hellwig (1982). It is well-known that precautionary motive can lead to efficiency loss due to excessive saving; see Aiyagari (1994) and Davila et al. (2012).

${ }^{2}$ I select and simplify some results from Rocheteau et al. (forthcoming); see therein for a general treatment. The discrete time setting in the introduction comes from Rocheteau et al. (2015). The discussion of perfect self-insurance in a monetary economy borrows from Wong (2016). See Lagos et al. (2017) for a recent survey on the literature of monetary theory; see Rocheteau and Nosal (2017) for a textbook introduction. The general welfare property of money with the risk-sharing role is still an open question; see Wallace (2014) for a conjecture.
}

DOI: https://doi.org/10.21144/eq1040102 
captures unexpected expenditures like car accidents and medical expenses (a top reason for bankruptcy in America). Liquidity shock is idiosyncratic, so it comes early for some agents but late for others; some agents experience only a few shocks over a long period of time, but some agents are hit often. ${ }^{3}$ Agents can store their endowments, thus in principle, agents always can self-insure against their liquidity shocks with private storage. In the design of the toy model, I do not force agents to use money - agents choose between money and storage - so the model has the potential to explain the fundamental reason for the emergence of money rather than merely begging the question. Furthermore, there is always coincidence of wants: every agent owns and consumes the same goods. If money is socially useful in this model, then it must be due to other reasons - in particular, I will show mathematically that when individuals hold money, it helps share others' liquidity risks.

\section{MODEL}

As a benchmark, I begin an economy without money. The economy is populated by a unit measure of risk-neutral agents. I first consider the time discrete and the horizon infinite. I need an infinite horizon for money to circulate in the latter section; otherwise, if the economy will terminate at a fixed date, then no agent will exchange his goods for money on the date before (since money has no future use), and hence on the date before before - by backward induction, no one will ever hold money in a finite horizon. ${ }^{4}$

Timing. The timing follows the literature of banking theory (e.g. Diamond and Dybvig [1983]). Each period has two stages. In the first stage, some agents are hit by liquidity shocks: when the shock hits, the agent needs to cover an expense of $\bar{y}>0$ units of goods, otherwise she is subject to an increasing loss for the amount falling short. Mathematically, it is conveniently captured by a quadratic loss function, $L(y)=-0.5 A \min (y-\bar{y}, 0)^{2}$, where $A>0$ captures the marginal loss and $y$ is the amount of goods the agent can raise to cover the liquidity shock. I simply refer to $y$ as early consumption as in the literature. Liquidity shocks are i.i.d. and occur with probability $\alpha \Delta>0$. In the second stage, each agent receives $h \Delta$ units of goods and consumes

\footnotetext{
${ }^{3}$ In a neat setting, Scheinkman and Weiss (1986) cleverly assume shocks are stochastic but alternate between two types of agent. This captures the redistribution effect, still the model remains highly tractable. Lippi et al. (2015) found that with this redistribution channel, the optimal monetary policy can be countercyclical.

${ }^{4}$ The backward induction argument hinges on the discreteness of time. In the continuous time, money can circulate in a finite horizon, but the monetary equilibrium, if it exists, is typically nonstationary. It is out of the scope of this review.
} 
$c \Delta$, pro rata to the length of period. In the absence of technologies enforcing and monitoring actions, debt contracts, either across stages or across periods, are not incentive feasible. However, agents can selfinsure against the liquidity shocks by storing any unconsumed goods in the second stage, subject to the depreciation rate $\delta$. In sum, the period-utility function is $\varepsilon L(y)+c \Delta$, where $\varepsilon \in\{0,1\}$ is the indicator of the liquidity shock with $\operatorname{Pr}(\varepsilon=1)=\alpha \Delta$. The discount factor across periods is $\exp (-r \Delta)$. The economy starts in the second stage of period 0 . The order of events does not quite matter when time becomes continuous.

Value. The choices of action are made with the following consideration. Contingent on the history of liquidity shocks, $\mathcal{H}^{t} \equiv\left\{\varepsilon_{1}, \varepsilon_{2}, \ldots \varepsilon_{t}\right\}$, agents choose the level of consumption and storage prepared for potential early consumption. Denote such a contingent plan as the functions, $C$ and $Y$, of history such that $c_{t}=C\left(\mathcal{H}^{t}\right)$ and $y_{t}=Y\left(\mathcal{H}^{t}\right)$. Also, denote $a_{t}$ as the level of storage brought to the second stage of $t$. Starting in the second stage of $t$, the value of storage is the expected discounted sum of the future utility and loss, which is given by

$$
\begin{aligned}
V_{t}= & \max _{C, Y}\left\{C\left(\mathcal{H}^{t}\right) \Delta+\mathbb{E}_{t} \sum_{s=t+1}^{\infty} e^{-r \Delta s}\left\{\varepsilon_{s} L\left[Y\left(\mathcal{H}^{s}\right)\right]+C\left(\mathcal{H}^{s}\right) \Delta\right\}\right\}, \\
& \text { given } a_{t} .
\end{aligned}
$$

With bounded endowments and depreciating storage, the level of storage is always bounded. Together with the fact that the loss function, $L(y)$, is bounded, the value of storage, $V_{t}$, cannot explode to infinity (positive or negative), and hence it satisfies the asymptotic boundary condition that $\lim _{s \rightarrow \infty} \mathbb{E}_{t} \exp (-r \Delta s) V_{s}=0$ almost surely. Then there exists a value function, $V(a)$, such that the value of storage, $V_{t}$, can be recursively expressed by the following Bellman equation

$$
\begin{aligned}
V_{t}=V(a)=\max _{c, a^{\prime}, y}\{c \Delta+ & \left.e^{-r \Delta}\left\{\alpha \Delta\left[L(y)+V\left(a^{\prime}-y\right)\right]+(1-\alpha \Delta) V\left(a^{\prime}\right)\right\}\right\} \\
\text { s.t. } a_{t} & =a, \\
a^{\prime} & =(1-\delta \Delta)(h \Delta-c \Delta+a) \\
c & \geq 0 \\
y & \in\left[0, a^{\prime}\right] .
\end{aligned}
$$

Denote the solutions to (1) as $c(a)$ and $y(a)$. Instead of making use of the entire history, $\mathcal{H}^{t}$, the current level of storage, $a_{t}=a$, is sufficient information for decision-making such that the agent's choices are given by $c_{t}=c(a)$ and $y_{t}=y(a)$. This recursive structure will be useful for analyzing the agent's infinite-horizon problem. 
The economic meaning of the Bellman equation (1) is as follows. According to (1), the typical agent chooses her consumption, $c$, the next-period storage (after depreciation applies), $a^{\prime}$, and the early consumption, $y$, in order to maximize her expected discounted continuation value in the next period. The budget identity specifies that the next-period storage is equal to the current income net of consumption multiplied by the gross depreciation factor. With probability $\alpha \Delta$, the agent receives a liquidity shock for early consumption. The maximal early consumption the agent can draw on is her entire level of storage, i.e. $y \leq a^{\prime}$. The choice of $y$ balances the trade-off between early consumption and leaving some storage for the future. With probability $1-\alpha \Delta$, the agent is not hit by a liquidity shock and enters the second stage with $a^{\prime}$. In sum, to self-insure against the liquidity shocks, the agent wants to maintain a sufficient level of storage at the cost of giving up current consumption and wasting resources to depreciation.

Self-insurance. Agents who are frequently hit by liquidity shocks consume less, hold less storage, and, in a vicious cycle, can become more vulnerable to future liquidity shocks. Should they share the liquidity risks, if possible? Actually, when their endowment, $h \Delta$, is sufficiently large, agents can achieve perfect self-insurance with constant storage. In this case, the marginal value of storage is constant at $V^{\prime}(a)=1$ for all $a$, and there is no need to share liquidity risks across agents in the economy. This case is well-studied in the literature after Lagos and Wright (2005). ${ }^{5}$ Here, I am interested in the case otherwise, but then the solution to (1) will feature occasionally binding constraints. To ease the analysis, I take the period length $\Delta$ to zero and the time becomes continuous. In this case, the flow of endowment, $h \Delta$, is so small compared to the magnitude of the liquidity shock, $\bar{y}$, that agents can never achieve perfect self-insurance. The rate of storage in the continuous time is given by

$$
\dot{a} \equiv \lim _{\Delta \rightarrow 0} \frac{a^{\prime}-a}{\Delta}=h-c-\delta a .
$$

\footnotetext{
${ }^{5}$ The appearance of perfect self-insurance does not necessarily depend on the riskneutral assumption. Wong (2016) illustrates examples with strictly concave utility functions. See the discussion therein for details. The key to perfect self-insurance is that agents can reach the target level of storage immediately after shocks, either by adjusting labor supply, consumption, portfolio, or a combination of these. Of course, achieving perfect self-insurance does not mean the first best.
} 
In the continuous time, the value function solves the following HamiltonJacob-Bellman (HJB) equation instead ${ }^{6}$ :

$r V(a)=\max _{c \geq 0, y \in[0, a]}\left\{c+V^{\prime}(a)(h-c-\delta a)+\alpha[L(y)+V(a-y)-V(a)]\right\}$,

where $V^{\prime}(a)$ denotes the first derivative of $V(a)$. Unlike the case of perfect self-insurance, generically $V^{\prime}(a)$ is varying in $a .^{7}$ The economic meaning of the HJB equation is as follows. When agents maximize their utility, the flow of the agent's value, $r V(a)$, is equal to the flow of the consumption utility, $c$, the rate the value changes due to storage, $V^{\prime}(a) \dot{a}$, and the expected change in the value due to the liquidity shocks, $\alpha[L(y)+V(a-y)-V(a)]$.

For the later derivation of the distribution, define $\Phi(a)$ as the maximal level of storage such that after a liquidity shock the agent will keep $a$ units of storage, given by

$$
\Phi(a) \equiv \max d \text { s.t. } d=y(d)+a,
$$

which means that the preshock storage, $\Phi$, is equal to the sum of the early consumption, $y(\Phi)$, and the postshock storage, $a$. In general, there can be multiple levels of preshock storage that lead to the same postshock storage; for example, when the agent always draws her entire storage for the early consumption, any level of preshock storage will lead to zero postshock storage. That is why in the definition of $\Phi, \mathrm{I}$ always pick the maximal one. I adopt the convention that $\Phi(a)=\infty$ if no solution to (3) exists.

Closed-form solutions. In general, the value function, $V(a)$, is the solution to the delayed differential equation (DDE), (2), satisfying the asymptotic boundary condition. Here, it is straightforward to verify

\footnotetext{
${ }^{6}$ Heuristically, the HJB equation can be derived as follows. Rearranging (1), I have $-\frac{V\left(a^{\prime}\right)-V(a)}{a^{\prime}-a} \frac{a^{\prime}-a}{\Delta}=\max \left\{c+e^{-r \Delta} \alpha\left[L(y)+V\left(a^{\prime}-y\right)-V\left(a^{\prime}\right)\right]+\frac{e^{-r \Delta}-1}{\Delta} V\left(a^{\prime}\right)\right\}$.

When $\Delta \rightarrow 0, \quad \mathrm{I}$ have $a^{\prime} \rightarrow a$. The right side above becomes $\max \{c+\alpha[L(y)+V(a-y)-V(a)]\}-r V(a)$. The first term on the left side becomes $-V^{\prime}(a)$ at the limit. The second term converges to $h-c-\delta a$. Collecting these terms, I have the HJB equation (2). It is only a heuristic derivation because it begs the question of proving the existence of $V(a)$ and, more challenging, that $V(z)$ is twice differentiable for the HJB to be well-defined. The complete proof is given by Rocheteau et al. (forthcoming), which utilizes the techniques of the viscosity solution.

${ }^{7}$ Suppose $V^{\prime}(a)=v$ for all $a$. The HJB equation becomes

$$
r(v a+\text { constant })=v(h-\delta a)+\max _{c \geq 0}(1-v) c+\max _{y \in[0, a]} \alpha[L(y)-v y] .
$$
}

The right side is linear in $a$ only if the constraint $y \leq a$ never binds. Then the firstorder condition implies that the agent can always finance a constant early consumption $y(a)=L^{\prime-1}(v)$ after any history, which is impossible. 
that the value function admits the following closed-form solution:

$$
V(a)=-\frac{v_{2}}{2} a^{2}+v_{1} a+v_{0}, \text { for } a \leq a^{*},
$$

where $v_{i}, i=0,1,2$, are constant given by

$$
\begin{aligned}
v_{2} & =\frac{\alpha A}{r+\alpha+2 \delta}, \\
v_{1} & =\frac{\alpha A \bar{y}-v_{2} h}{r+\alpha+\delta}, \\
v_{0} & =\frac{v_{1} h}{r}-\frac{\alpha A}{2 r} \bar{y}^{2}, \\
a^{*} & =\left(v_{1}-1\right) / v_{2} .
\end{aligned}
$$

The optimal choices for consumption and early consumption are functions of storage given $b y^{8}$

$$
\begin{aligned}
& c(a)=\left\{\begin{array}{l}
0, \text { for } a<a^{*}, \\
h-\delta a^{*}, \text { for } a=a^{*} .
\end{array}\right. \\
& y(a)=a, \text { for } a \leq a^{*} .
\end{aligned}
$$

The rate of storage, $\dot{a}=s_{a}(a)$, is given by

$$
s_{a}(a)=h-c(a)-\delta a .
$$

The typical pattern of storage is illustrated by Figure 1. Whenever a liquidity shock hits, the agent will draw all her storage available for early consumption and then "restart" the accumulation. The agent accumulates her storage toward the target level $a^{*}$. During this process, she stores all her endowment and consumes nothing. By doing so, she can build up the target level of storage the quickest. Once she reaches the target, she starts consumption at the rate that maintains her storage at the target, i.e., the endowment after deducting depreciation. The target level of storage balances current consumption and self-insurance for future liquidity shocks: maintaining a higher target gives better protection against the liquidity shocks, but it wastes more resources to depreciation and leads to lower consumption.

Remark. The model has a closed-form solution because it is designed to make use of the following properties. Suppose the value function, $V(a)$, is a polynomial of degree $n$ and the consumption function, $c(a)$, is of degree $n_{c}$. Notice that the second term on the right side of HJB equation (2) involves a product of a term of degree $n-1$ and a sum of degrees of 0,1 , and $n_{c}$, so in general the resulting product is a term

\footnotetext{
${ }^{8}$ For these to hold, I have implicitly assumed the parameterization such that $a^{*} \in$ $[0, \bar{y}], c\left(a^{*}\right) \geq 0$, and $L^{\prime}\left(a^{*}\right) \geq v_{1}$. It requires, for example, the marginal loss, $A$, to be sufficiently high such that an agent prefers to fully deplete all of her storage rather than leave some for the future. See Rocheteau et al. (forthcoming) for details.
} 
Figure 1 A Time Path of Storage

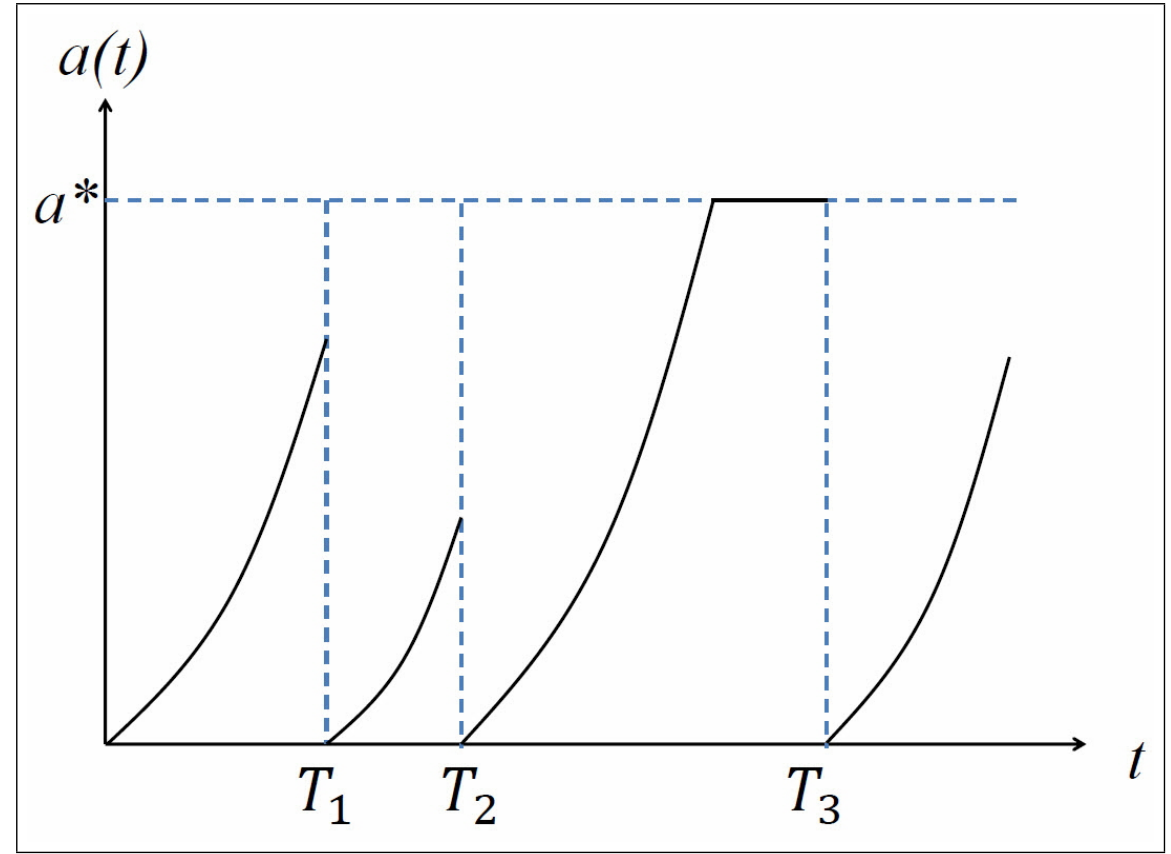

of degrees of $\max \left(n, n-1+n_{c}\right)$. If the consumption utility is linear, then the consumption is bang-bang so $n_{c}=0$ almost everywhere. If the equilibrium features full depletion, i.e., $y(a)=a$, then the last term of (2) is of degree $\max \left(n_{L}, n\right)$. Setting $n_{L}=2$, a closed-form solution of $V$ with $N=2$ will match the degree on the both sides of (2).

Distribution. In this economy, agents have different histories of liquidity shocks, so they are different from one another in the level of storage. Are there a lot of agents poor in storage and hence severely exposed to the liquidity shocks? If so, then there will be potential social gain from risk sharing by having an alternative market structure. To answer this question, I need to know the distribution of storage in this economy. Denote $F_{a}(a) \in[0,1]$ the share of agents with weakly less than $a$ units of storage, also known as the distribution function. In the continuous time, the distribution function simply solves the following Kolmorgorov forward equation (KFE):

$$
s_{a}(a) F_{a}^{\prime}(a)=\alpha\left[F_{a}[\Phi(a)]-F_{a}(a)\right], \text { for all interior } a,
$$

where $F_{a}^{\prime}(a)$ denotes the first derivative of $F(a)$-the density function. The mechanical meaning of the KFE is as follows. Consider the group 
of agents with storage weakly less than $a$. Let's call this group of agents $\mathcal{A}$. The size of $\mathcal{A}$ is $F_{a}(a)$ by definition. I want to check the change in the size of $\mathcal{A}$ after a very short amount of time, $\Delta \cong 0$. For any member of $\mathcal{A}$ with storage strictly less than $a$, i.e., those with $a^{\prime}$ where $a^{\prime}<a$, their storage will increase by $s_{a}\left(a^{\prime}\right) \Delta$ units if they do not receive any liquidity shock during the spell of $\Delta$. When $\Delta$ is very small, the level of storage after $\Delta$ is given by $a^{\prime}+s_{a}\left(a^{\prime}\right) \Delta \leq a$. If they do receive a liquidity shock, then according to the solution (6) they draw all their storage, $y\left(a^{\prime}\right)=a^{\prime}$, for the early consumption, and hence their postshock storage is zero. In either case, the level of storage after $\Delta$ is still weakly less than $a$, so they remain in $\mathcal{A}$ and the size of $\mathcal{A}$ does not change. Now, consider the "border" agents to $\mathcal{A}$ with exactly $a^{\prime}=a$. The size of the border agents is, roughly speaking, given by the density function, $F_{a}^{\prime}(a) \partial a$. In the continuous time, the outflow of the border agents is $s_{a}(a) \Delta F_{a}^{\prime}(a)$ : the rate they are leaving the border group, $s_{a}(a) \Delta / \partial a$, multiplied by the size of the border group, $F_{a}^{\prime}(a) \partial a$. On the other hand, there are also agents who did not belong to $\mathcal{A}$ until the liquidity shocks. These agents must have storage strictly greater than $a$ before the liquidity shock but less than $a$ after the shock. The size of this group of potential "immigrants" is $F_{a}[\Phi(a)]-F_{a}(a)$. In the continuous time, the inflow to $\mathcal{A}$ from the potential immigrants is $\alpha \Delta\left[F_{a}[\Phi(a)]-F_{a}(a)\right]$ : by the law of large numbers, there is a share $\alpha \Delta$ of the potential immigrants hit by liquidity shocks. According to the KFE (8), the distribution of $a$ is stationary when the outflow is equal to the inflow for any $\mathcal{A}$.

In general, the distribution function, $F_{a}(a)$, is the solution to the DDE (8) satisfying the boundary conditions $F_{a}(0)=0$ and $F_{a}(a)=1$ for all $a \geq a^{*}$ : there is no agent with storage less than 0 or strictly greater than $a^{*}$. Since agents always draw all the storage for early consumption, i.e., $y(a)=a$, the real balances before a shock are given by $\Phi(a)=\infty$ for all $a>0$. It is straightforward to verify that the distribution function follows a truncated beta distribution:

$$
F_{a}(a)=\left\{\begin{array}{l}
1-\left(1-\frac{\delta}{h} a\right)^{\alpha / \delta}, \text { if } a<a^{*}, \\
1, \text { if } a \geq a^{*} .
\end{array}\right.
$$

Figure 2 illustrates the distribution $F_{a}(a)$. The distribution is smooth everywhere except at $a=a^{*}$ with the point mass $1-F_{a}\left(a^{*}\right)$. Once they reach the target $a^{*}$, agents stop accumulating further storage so there is a positive measure of agents with exactly $a^{*}$ units of storage. The aggregate storage is given by

$$
\mathbb{E}(a)=\int_{0}^{a^{*}}\left[1-F_{a}(a)\right] d a=\frac{h}{\delta+\alpha}\left[1-\left(1-\frac{\delta}{h} a^{*}\right)^{\alpha / \delta+1}\right] .
$$




\section{Figure 2 The Distribution Function}

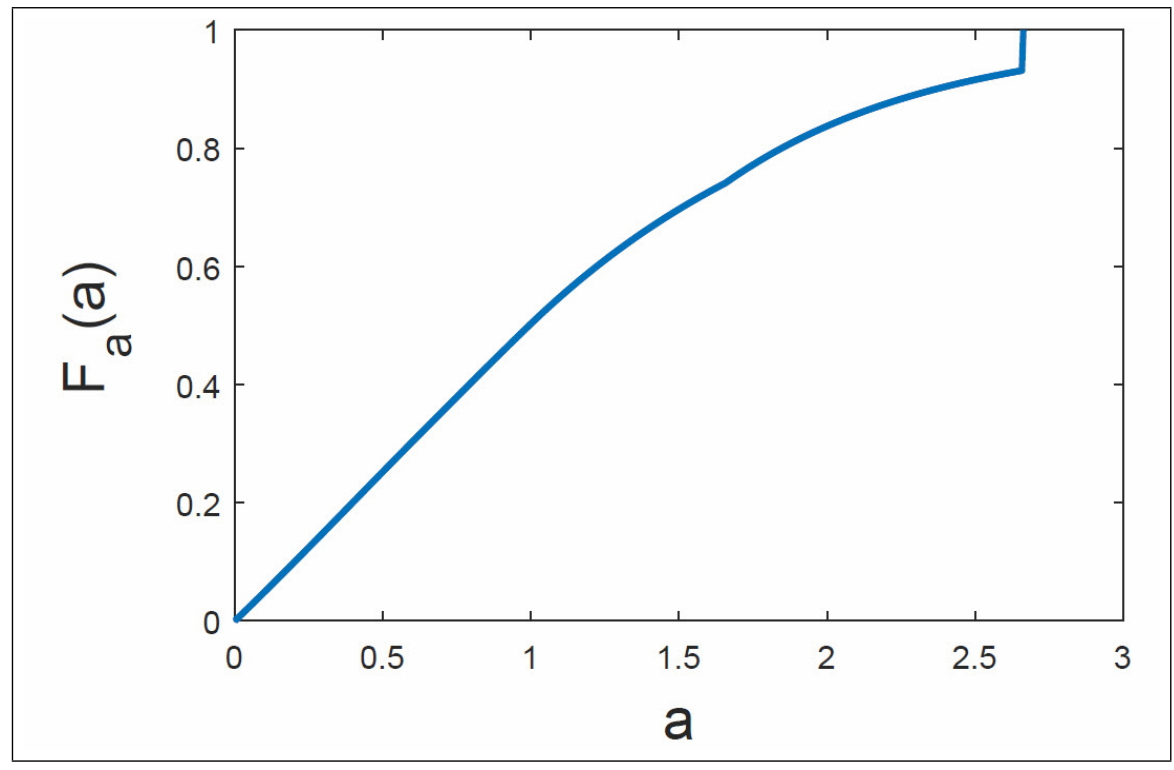

The following proposition summarizes how the fundamentals change the aggregate storage.

Proposition 1 The aggregate storage, $\mathbb{E}(a)$, is increasing in the magnitude of the liquidity shock, $\bar{y}$.

Proof. It follows the fact that $a^{*}$ is increasing in $\bar{y}$.

Proposition 1 states that liquidity shock raises the aggregate storage. This is because when agents expect bigger liquidity shocks, they want to prepare a higher level of storage on average for self-insurance.

Welfare formula. The (utilitarian) welfare of this economy is the total sum of the utility and loss across agents, which is given by

$$
\mathcal{W}_{a}=\int_{0}^{\infty}[c(a)+\alpha L[y(a)]] d F_{a}(a) .
$$

The first term is given by

$$
\int_{0}^{\infty} c(a) d F_{a}(a)=c\left(a^{*}\right)\left[1-F_{a}\left(a^{*}\right)\right]=h\left(1-\frac{\delta}{h} a^{*}\right)^{\alpha / \delta+1}=h-(\delta+\alpha) \mathbb{E}(a) .
$$

Since the economy features full depletion, the second term is given by

$$
\int_{0}^{\infty} L[y(a)] d F_{a}(a)=-\frac{A}{2} \int_{0}^{a^{*}}(\bar{y}-a)^{2} d F_{a}(a)=-\frac{A}{2}\left[[\bar{y}-\mathbb{E}(a)]^{2}+V A R(a)\right] .
$$


Collecting these terms, the welfare can be written as the following mean-variance formula:

$\mathcal{W}_{a}=h-(\delta+\alpha) \bar{y}+\frac{(\delta+\alpha)^{2}}{2 \alpha A}-\frac{\alpha A}{2}\left[\bar{y}-\frac{\delta+\alpha}{\alpha A}-\mathbb{E}(a)\right]^{2}-\frac{\alpha A}{2} V A R(a)$.

The following proposition summarizes how the welfare depends on the distribution.

Proposition 2 The welfare of the self-insurance economy, $\mathcal{W}_{a}$, is

(a) negatively related to the dispersion of individual storage, $V A R(a)$, and

(b) positively related to the aggregate storage, $\mathbb{E}(a)$, if and only if $\mathbb{E}(a) \leq \bar{y}-(\delta+\alpha) /(\alpha A)$.

Proposition 2 states that dispersion and aggregate level of storage are sufficient statistics for welfare. Inequality in storage reduces welfare because it means there are a lot of storage-poor agents exposed to the liquidity shocks. The effect of the aggregate storage on the welfare is not monotone. When the aggregate storage is small, such that $\mathbb{E}(a) \leq \bar{y}-(\delta+\alpha) /(\alpha A)$, an increase in the aggregate storage allows better protection against the liquidity shocks on average and raises the welfare. However, when the aggregate storage is large, such that $\mathbb{E}(a) \geq \bar{y}-(\delta+\alpha) /(\alpha A)$, an increase in the aggregate storage diverts too many resources from consumption on average, which reduces the welfare. This threshold is increasing in the marginal loss of the liquidity shock, $A$, because agents need more protection against the liquidity shock when its loss becomes more costly. For a similar reason, the threshold is increasing in the probability of the liquidity shock, $\alpha$, but decreasing in the depreciation rate, $\delta$.

\section{EFFICIENCY LOSS TO SELF-INSURANCE}

In this economy there is unit measure of uncountably many agents. One advantage to a mass society is that it has the critical mass to eliminate individual shocks by pooling resources. What should agents do collectively if they can coordinate for the best of themselves? The situation is the same as when there is one "representative" agent, the planner, solving the following problem

$$
\begin{gathered}
\max _{c^{*}, y^{*}}\left\{c^{*}+\alpha L\left(y^{*}\right)\right\} \text { s.t. } \\
h \geq c^{*}+\alpha y^{*} .
\end{gathered}
$$

The planner maximizes the total flow of the consumption utility, $c$, and minimizes the total flow of the loss to liquidity shocks, $\alpha L(y)$. The 
resource constraint faced by the planner is that the total consumption and early consumption are not greater than the total endowments pooled by agents. The planner's solution, also known as the first best, is given by

$$
\begin{aligned}
& y^{*}=\bar{y}-A^{-1} \\
& c^{*}=h-\alpha\left(\bar{y}-A^{-1}\right) .
\end{aligned}
$$

In the first best, agents pay a premium $\alpha y^{*}$ to insure the liquidity shocks by guaranteeing $y^{*}$ units of early consumption. Compared with the first best, there are two sources of efficiency loss in the self-insurance economy. On one hand, when agents self-insure with storage, the average consumption is lower, $\mathbb{E}[c(a)]<c^{*}$, because some resources are wasted to depreciation. On the other hand, self-insurance by building up storage is a slow process due to depreciation and limited endowment. Compared with the first best, the self-insurance economy features less protection against the liquidity shocks on average, $\mathbb{E}[a]<y^{*}$, especially to the agents with less storage. It echoes Proposition 2 that the welfare is increasing in the inequality of storage. In the first best, every agent can perfectly share the liquidity risk and there is no inequality.

\section{SHARING RISKS WITH MONEY}

Now consider an intrinsically useless object called money. Maintained by a central bank, the stock of money, $M_{t}$, grows at the rate $\pi$, where $\pi \in[0, \delta]$. The central bank does not consume anything or withhold any resources, so the simplest way of injecting new money to the economy is the helicopter drop: the central bank creates and transfers a lump sum $\pi M_{t}$ of money to every agent. It is also the same as the policy where the central bank purchases endowments from agents with newly printed money and then transfers all the purchased endowments to agents.

In other words, the central bank keeps printing for agents increasing amounts of paper, so-called money. How can it change the economy? Potentially, there is a market where agents can buy or sell endowment with money (they are not forced to do so). Denote as $\phi_{t}$ the real price of money in terms of goods, i.e., each unit of money can buy $\phi_{t}$ units of goods and its negative growth rate, $-\dot{\phi}_{t} / \phi_{t}$, is simply the inflation rate: the loss rate of the real purchasing power of money. The real price of money is determined by agents' net demand and the central bank's supply. The situation where money cannot be exchanged for anything is captured by $\phi_{t}=0$. I first guess (and verify later) that agents will no longer store any endowment but will hold money instead. In the 
continuous time, the budget constraint is given by

$$
\dot{m}_{t}=\frac{h+\pi M_{t}-c_{t}}{\phi_{t}} .
$$

That is, the change in money holding, $\dot{m}_{t}$, is equal to the monetary amount of income not consumed, $\left(h+\pi M_{t}-c_{t}\right) / \phi_{t}$. In the stationary equilibrium, if it exists, the total purchasing power of money should be constant such that $\phi_{t} M_{t}$ remains the same over time. It implies

$$
-\frac{\dot{\phi}_{t}}{\phi_{t}}=\pi
$$

In other words, inflation is always a monetary phenomenon in the sense that the change in the real price of money is driven by the increase of the money supply. Denote the individual real balances as $z_{t}=\phi_{t} m_{t}$ and the aggregate real balances as $Z=\phi_{t} M_{t}$, then the budget constraint in the stationary equilibrium is given by

$$
\dot{z}_{t}=h+\pi Z-c_{t}-\pi z_{t} .
$$

That is, the change in the real balances of money is the income not consumed, $h+\pi Z-c_{t}$, minus the loss of real balances due to inflation, $\pi z_{t}$. Similar to the previous section, the value function of holding money solves the following HJB equation

$r W(z)=\max _{c \geq 0, y \in[0, z]}\left\{c+W^{\prime}(z)(h+\pi Z-c-\pi z)+\alpha[L(y)+W(z-y)-W(z)]\right\}$.

It is straightforward to verify that the value function admits the following closed-form solution:

$$
W(z)=-\frac{w_{2}}{2} z^{2}+w_{1} z+w_{0}, \text { for } z \leq z^{*}
$$

where $w_{i}, i=0,1,2$, are constant, given by

$$
\begin{aligned}
w_{2} & =\frac{\alpha A}{r+\alpha+2 \pi}, \\
w_{1} & =\frac{\alpha A \bar{y}-w_{2}(h+\pi Z)}{r+\alpha+\pi}, \\
w_{0} & =\frac{w_{1}(h+\pi Z)}{r}-\frac{\alpha A}{2 r} \bar{y}^{2}, \\
z^{*} & =\left(w_{1}-1\right) / w_{2} .
\end{aligned}
$$

The optimal choices for consumption and early consumption are functions of real balances given by

$$
\begin{aligned}
& c(z)=\left\{\begin{array}{l}
0, \text { for } z<z^{*}, \\
h+\pi Z-\pi z^{*}, \text { for } z=z^{*} .
\end{array}\right. \\
& y(z)=z, \text { for } z \leq z^{*} .
\end{aligned}
$$


The rate of accumulating real balances, $\dot{z}=s_{z}(z)$, is given by

$$
s_{z}(z)=h+\pi Z-c(z)-\pi z .
$$

The distribution is given by the following KFE

$$
s_{z}(z) F_{z}^{\prime}(z)=\alpha\left[1-F_{z}(z)\right], \text { for all interior } z .
$$

The closed-form solution to the distribution function of real balances is given by

$$
F_{z}(z)=\left\{\begin{array}{l}
1-\left(1-\frac{\pi}{h+\pi Z} z\right)^{\alpha / \pi}, \text { for } z<z^{*}, \\
1, \text { for } z \geq z^{*}
\end{array}\right\}, \text { if } \pi>0,
$$

or

$$
F_{z}(z)=\left\{\begin{array}{l}
1-\exp \left(-\frac{\alpha}{h} z\right), \text { for } z<z^{*}, \\
1, \text { for } z \geq z^{*} .
\end{array}\right\}, \text { if } \pi=0,
$$

where $Z$ is the fixed point solving

$$
Z=\mathbb{E}(z)=\frac{h+\pi Z}{\pi+\alpha}\left[1-\left(1-\frac{\delta}{h+\pi Z} z^{*}\right)^{\alpha / \pi+1}\right] .
$$

The following lemma shows that $Z$ is well-defined.

Lemma 1 There exists a unique solution $Z$ to (17).

Proof. The fixed point $Z$ exists because the left side of (17) is smaller than the right side for $Z=0$ but becomes larger than the right side for $Z=\infty$, so there must exist some $Z$ where the left side is equal to the right side. The fixed point is also unique because the right side, as a function of $Z$, has a slope less than unity.

Equation (17) captures the market-clearing condition for money: the left side captures the money supply $Z=\phi_{t} M_{t}$ in real terms, and the right side captures the aggregate money demand by agents, $\mathbb{E}(z) \equiv \int z d F_{z}(z)$. Similar to Proposition 1, the following proposition establishes that the liquidity shock increases the money demand.

Proposition 3 The aggregate real balances of money, $\mathbb{E}(z)$, is increasing in the magnitude of the liquidity shock, $\bar{y}$.

Proof. The left side of (17) is a function of $Z$ with a unit slope. The right side has a slope less than unity. An increase in $\bar{y}$ shifts up the right side via $z^{*}$, so the fixed point $Z$ increases.

Like storage, agents in this economy hold money in order to selfinsure against the liquidity shocks. Therefore, the more severe the magnitude of the liquidity shock, the more money agents hold. The value of money is measured by the equilibrium price, which is given by

$$
\phi_{t}=\frac{Z}{M_{t}}=\frac{Z}{M_{0}} \exp (-\pi t) .
$$


Indeed, the fact that $\phi_{t}>0$ verifies that money circulates in this economy. Finally, think of the inflation rate, $-\dot{\phi}_{t} / \phi_{t}$, as the depreciation rate of a new storage technology, which is preferred by agents to the original storage technology, since the depreciation rate with money is lower, i.e. $-\dot{\phi}_{t} / \phi_{t}=\pi \leq \delta$. It verifies the premise that the use of money will "crowd out" individual storage.

Having shown that money circulates despite the fact that money is intrinsically useless and there is always a coincidence of wants, now I want to check whether or not the economy is better off after the introduction of money. To do so, I need to compare the welfare to the self-insurance economy. The welfare in the monetary economy is given by

$$
\mathcal{W}_{z}=\int_{0}^{\infty}[c(z)+\alpha L[y(z)]] d F_{z}(z) .
$$

The first term is given by

$$
\int_{0}^{\infty} c(z) d F_{z}(z)=h-\alpha \mathbb{E}(z)
$$

where I have made use of the fact that $Z=\mathbb{E}(z)$ in the equilibrium. Since the economy features full-depletion, the second term is given by

$$
\int_{0}^{\infty} L[y(z)] d F_{z}(a z)=-\frac{A}{2}\left[[\bar{y}-\mathbb{E}(z)]^{2}+V A R(z)\right] .
$$

Collecting these terms, the welfare can be written as the similar meanvariance formula:

$$
\mathcal{W}_{z}=c^{*}-\frac{\alpha}{2 A}-\frac{\alpha A}{2}\left[y^{*}-\mathbb{E}(z)\right]^{2}-\frac{\alpha A}{2} V A R(z) .
$$

Proposition 4 The welfare of the monetary economy is

(a) negatively related to the dispersion of real balances, $V A R(z)$, and

(b) positively related to the aggregate real balances, $\mathbb{E}(z)$, if and only if $\mathbb{E}(z) \leq y^{*}$.

Similar to the self-insurance economy, inequality in money holding reduces the welfare because it means there are a lot of money-poor agents exposed to the liquidity shocks. The aggregate real balances of money raise the welfare if and only if the aggregate real balances are less than the first-best level of early consumption, $\mathbb{E}(z) \leq y^{*}$, i.e., when agents do not hold more money on average than they should in the first best.

Now I am ready to conclude the social role of money with the following proposition. 
Proposition 5 Welfare is higher under the monetary economy than the self-insurance economy, i.e., $\mathcal{W}_{z}>\mathcal{W}_{a}$.

Proof. Notice that welfare is also equal to $\mathcal{W}_{a}=r \int V(a) d F_{a}(a)$ and $\mathcal{W}_{z}=r \int W(z) d F_{z}(z)$, i.e., the average value in the economy. It is straightforward, although tedious, to check the closed-form solutions that $V(x)<W(x)$ and $z^{*}<a^{*}$. Intuitively, the fact that money depreciates at a lower rate and agents receive an additional transfer $\pi Z$ means that the agent with wealth $x$ has higher value in the monetary economy, for any $x$. Finally, from the KFE the distribution functions are given by

$$
\begin{aligned}
\log \left[1-F_{a}(a)\right] & =\int_{0}^{a} \frac{-\alpha}{s_{a}(x)} d x, \\
\log \left[1-F_{z}(z)\right] & =\int_{0}^{z} \frac{-\alpha}{s_{z}(x)} d x .
\end{aligned}
$$

Given the fact that $s_{z}(x)>s_{a}(x)$, I have $1-F_{z}(x)>1-F_{a}(x)$, i.e. there are more wealthy agents in the monetary economy. Combining the facts that $1-F_{z}(x)>1-F_{a}(x)$ and $V(x)<W(x)$, I prove that $\mathcal{W}_{a}=r \int V(a) d F_{a}(a)<r \int W(z) d F_{z}(z)=\mathcal{W}_{z}$.

If the inflation rate is not too high that $\pi \leq \delta$, then the monetary economy is always more socially desirable than the self-insurance economy with private storage only. But what is the optimal inflation rate? In general, it is not zero, and finding the optimal rate is a quantitative exercise involving the following trade-off. A higher inflation hurts the return of money (inflation as a tax to money holding) and hence discourages its use as a precautionary saving. A higher inflation, however, enables generous monetary transfers and promotes social sharing of liquidity risks. The second effect dominates when $h$ is low (self-insurance is low because income is low) or $\alpha$ is high (liquidity shock comes too frequent to maintain a sufficient level of self-insurance).

\section{CONCLUSION}

As rightly pointed out by Winston Churchill in my opening quotation, capitalism that builds on money and market inevitably results in unequal sharing of blessing and misery. A lesson from this review is, however, that money can well be our best response to mitigate unequal sharing of blessing and misery, so economy without money is even worse. How can money improve social welfare? My model illustrates three channels. Firstly, the usage of money mimics, though not perfectly, the first-best allocation. When agents hold and accumulate money, they sell their endowments to others who want to sell money. Let's call the former the seller (of endowment) and the latter the buyer 
(of endowment). In the monetary economy, these buyers are exactly the ones who are hit by the liquidity shocks. When the buyers buy endowments and sell money to the sellers in the market, resources are efficiently transferred from nonshocked agents to the shocked agentsthe monetary mechanism of risk sharing. Why do the sellers want to buy money? Because when they sell their endowments, the sellers actually buy an insurance against the future liquidity shocks, and the insurance premium is essentially the consumption forgone for acquiring money in the market. It is exactly what should happen in the first best, illustrated in Section 2. Secondly, money allows agents to save with other agents, instead of decentralized storage. And saving in money gives higher returns to agents, comparing the loss due to inflation with the loss due to depreciation. It avoids wasting resources to depreciation and allows more resources for consumption. Finally, agents who are poor in money are the unlucky ones frequently hit by the liquidity shocks. When the central bank keeps injecting new money into the economy, it helps poor agents build up their purchasing power. As a result, agents in the monetary economy are better prepared for the liquidity shocks. 


\section{REFERENCES}

Aiyagari, S. Rao. 1994. "Uninsured Idiosyncratic Risk and Aggregate Saving." Quarterly Journal of Economics 109 (August): 659-84.

Bewley, Truman. 1980. "The Optimum Quantity of Money." In Models of Monetary Economies, edited by John H. Kareken and Neil Wallace. Minneapolis: Federal Reserve Bank of Minneapolis. 169-210.

Bewley, Truman. 1983. "A Difficulty with the Optimum Quantity of Money." Econometrica 51 (September): 1485-1504.

Davila, Julio, Jay H. Hong, Per Krusell, and José-Victor Ríos-Rull. 2012. "Constrained Efficiency in the Neoclassical Growth Model with Uninsurable Idiosyncratic Shocks." Econometrica 80 (November): 2431-67.

Diamond, Douglas W., and Philip H. Dybvig. 1983. "Bank Runs, Deposit Insurance, and Liquidity." Journal of Political Economy 91 (June): 401-19.

Hellwig, M. 1982. "Precautionary Money Holding and the Payment of Interest on Money." CORE Discussion Paper 8236 (September).

Lagos, Ricardo, Guillaume Rocheteau, and Randall Wright. 2017. "Liquidity: A New Monetarist Perspective." Journal of Economic Literature 55 (June): 371-440.

Lagos, Ricardo, and Randall Wright. 2005. "A Unified Framework for Monetary Theory and Policy Analysis." Journal of Political Economy 113 (June): 463-84.

Lippi, Francesco, Stefania Ragni, and Nicholas Trachter. 2015. "Optimal Monetary Policy with Heterogeneous Money Holdings." Journal of Economic Theory 159 (September): 339-68.

Rocheteau, Guillaume, and Ed Nosal. 2017. Money, Payments, and Liquidity, 2nd Ed. Cambridge, Mass.: MIT Press.

Rocheteau, Guillaume, Pierre-Olivier Weill, and Tza-Nga Wong. 2015. "Working through the Distribution: Money in the Short and Long Run." Working Paper 21779. Cambridge, Mass.: National Bureau of Economic Research. (December).

Rocheteau, Guillaume, Pierre-Olivier Weill, and Tza-Nga Wong. Forthcoming. "A Tractable Model of Monetary Exchange with Ex-Post Heterogeneity." Theoretical Economics. 
Scheinkman, Jose A., and Laurence Weiss. 1986. "Borrowing

Constraints and Aggregate Economic Activity." Econometrica 54 (January): 23-45.

Wallace, Neil. 2014. "Optimal Money Creation in 'Pure Currency'

Economies: a Conjecture." Quarterly Journal of Economics 129 (February): 259-74.

Wong, Tza-Nga. 2016. "A Tractable Monetary Model under General Preferences." Review of Economic Studies 83 (January): 402-20. 